\title{
Propostas de reforma do auxílio-reclusão no Congresso Nacional: impacto e embates políticos
}

Otávio Dias de Souza Ferreira*

\begin{abstract}
Resumo
Tramitaram na última Legislatura (2011-2014) no Congresso Nacional brasileiro quatro propostas de emenda constitucional sobre o benefício penitenciário chamado de auxílioreclusão, destinado aos dependentes de pessoas presas com vínculos com a Previdência Social. As propostas variavam entre a ampliação do público beneficiado, a restrição dos segurados e a extinção completa do benefício. Inicialmente, promove-se uma avaliação dos impactos que 0 benefício previdenciário apresenta para o Estado e para os segurados. No momento seguinte, a partir das justificativas, conteúdos e status no processo legislativo das propostas, são analisadas as suas perspectivas, considerando a mudança na correlação de forças verificada após as eleições de 2014. Mostra-se como se afigura improvável, no novo cenário político, a aprovação de alguma das propostas de modificação do auxílio-reclusão.
\end{abstract}

\section{Palavras-chave}

Auxílio-reclusão. Reforma constitucional. Disputas políticas.

\begin{abstract}
In the last Legislature (2011-2014) of the Brazilian National Congress, four constitutional amendment proposals were carried out regarding the penitentiary benefits known as the inmate welfare assistance, which is destined to the dependents of incarcerated people connected to the Social Security. The proposals varied among the increase of the benefited public, the restriction of the insured and the benefit's complete extinction. Initially, they promote an evaluation of the impacts such benefits present to the State and the insured. Soon after, based on justifications, contents and status in the legislative process of the proposals, the perspectives are analyzed, considering the change in the power correlation verified after the 2014 elections. It is revealed how unlikely it seems, in the new political setting, for any of the modification proposals in the inmate welfare assistance to be approved.
\end{abstract}

\section{Keywords}

Inmate welfare assistance. Constitutional reform. Political debates.

\footnotetext{
* Otávio Dias de Souza Ferreira é Doutorando em Ciência Política pela Faculdade de Filosofia, Letras e Ciências Humanas da Universidade de São Paulo (FFLCH/USP), com bolsa de estudos da Coordenação de Aperfeiçoamento de Pessoal de Nível Superior (CAPES); e pesquisador do Núcleo Direito e Democracia do CEBRAP. E-mail: euotavio@gmail.com.
} 


\section{Introdução}

O auxílio-reclusão é um benefício previdenciário - não acidentário - pago pelo Ministério da Previdência Social apenas aos dependentes do segurado punido com a privação de liberdade, nos regimes fechado ou semiaberto. Não é a pessoa presa quem é beneficiada, mas apenas seus dependentes, sejam eles seu cônjuge ou companheiro, seus filhos, pais ou mesmo seus irmãos. Sua origem remonta aos anos 1930, mas ele vem sofrendo ao longo das décadas algumas alterações legais (CHIES; PASSOS, 2012. DANTAS; RODRIGUES, 2009).

A última alteração mais significativa foi introduzida dez anos após a Constituição Federal. Segundo a redação original da Carta de 1988, o benefício previdenciário do auxílio-reclusão era devido a todos os dependentes de pessoas presas que se enquadrassem na qualidade de seguradas da Previdência. A Emenda Constitucional no 20, de 1998, restringiu o benefício apenas para os dependentes de segurados de baixa-renda ${ }^{1}$.

Diferentes Propostas de Emenda à Constituição (PECs) tramitaram no Congresso Nacional na última Legislatura (2011-2014) tratando da reforma do auxílio-reclusão: uma pretendia aumentar o público beneficiado, outra buscava restringi-lo, além de outras duas apresentadas no segundo semestre de 2013, em meio à turbulência gerada pelas manifestações populares de junho daquele ano, que visavam extinguir o benefício.

Muitas informações deturpadas e inverídicas vêm sendo amplamente divulgadas há anos em redes sociais e servem para persuadir parcelas da opinião pública a protestar contra o auxílio-reclusão (CHIES; PASSOS, 2012.). Diz-se, por exemplo, que se trata de uma "bolsa-bandido", beneficiando diretamente o próprio autor de crime, e não seus dependentes. Afirma-se que todos os presos fazem jus ao auxílio-reclusão, enquanto apenas uma pequena minoria é beneficiada. Sustenta-se que todos os cidadãos financiam esse benefício, enquanto um requisito para a concessão do benefício é a contribuição prévia. Alega-se que a concessão desse benefício é responsável

\footnotetext{
${ }^{1}$ Raupp (2009) critica severamente essa alteração constitucional operada pela Emenda n. 20/1998, acusando-a de inconstitucional por ter modificado a própria natureza do auxílioreclusão, destoando dos demais benefícios previdenciários e aproximando-o dos benefícios assistenciais, uma vez que passou a se submeter ao princípio da seletividade.
} 
por um rombo na Previdência Social, enquanto ele ocupa apenas uma parcela ínfima dos gastos do sistema previdenciário nacional. Quem acredita nessas afirmações parece desconhecer o que é esse benefício e como funciona a sua concessão.

Como qualquer direito ligado às populações encarceradas, em geral, não goza de popularidade perante a população, um fenômeno que não é exclusivo de nosso país, como já mostrava Michel Foucault (1989). Estudos já mostraram como certos grupos conservadores têm mobilizado de forma pejorativa no Brasil a ideia de direitos de presos, desde pelo menos o início dos anos 1980 (CALDEIRA, 1991; CARDIA, 1995; HOLSTON, 2008).

A impopularidade do benefício do auxílio-reclusão tem se confirmado amplamente em enquete promovida pelo Portal da Câmara dos Deputados (BRASIL, s.d.2). De pouco mais de um milhão de votantes - entre janeiro de 2014 e novembro de 2014 - cerca de 95\% deles concordaram com a extinção do auxílio-reclusão para ser substituído por um benefício para a vítima direta de crimes. A tal enquete propõe a seguinte questão: "Você concorda com o fim do auxílio-reclusão e a criação de um benefício para as vítimas dos crimes?”. Apresenta um link para o participante se informar melhor sobre o assunto. Mas, ao acessar o endereço, há apenas a apresentação da PEC n. 304/2013, com o texto da proposta e a opinião de sua autora, não se prestando a maiores esclarecimentos. Falta um contraponto.

Em um primeiro momento deste artigo, pretende-se iluminar, com base em pesquisas e análise de dados oficiais, o impacto que o benefício previdenciário tem para o Governo e para os segurados e seus familiares. No segundo momento, a intenção é apresentar a exposição das justificativas e conteúdos das propostas legislativas ${ }^{2}$, para se identificar a forma pela qual o debate vem sendo proposto no Legislativo. Em seguida, são analisadas as perspectivas das PECs, considerando o cenário político e institucional e a mudança na correlação de forças verificada após as eleições de 2014.

\footnotetext{
${ }^{2}$ Todos os textos e justificativas mencionados a seguir encontram-se na página eletrônica da Câmara dos Deputados (BRASIL, s.d.1) e do Senado (BRASIL, s.d.4).
} 


\section{Impactos do Auxílio-Reclusão}

A formação de alguma convicção sobre uma reforma no instituto do auxílioreclusão requer a consciência dos impactos que esse benefício tem para o Estado e para os segurados e seus familiares. Trata-se de uma temática complexa. Na leitura das propostas e suas justificativas, há diversos elementos utilizados para o convencimento dos demais parlamentares, mas se percebe alguma carência de informações sobre a realidade social e econômica na qual ele se insere.

Nas campanhas contra o auxílio-reclusão promovidas durante e após junho de 2013, um argumento que era proferido referia-se a um suposto "rombo" que tal benefício previdenciário provocaria no orçamento da Previdência Social. Para verificar sua procedência, é preciso analisar alguns dados oficiais.

Nos gráficos 1 e 2, podemos observar, no período entre 1994 e 2008, os efeitos práticos da mudança, que implicou na alteração da redação original da Constituição, por conta da Emenda Constitucional n. 20/1998, que restringiu o público atendido inicialmente pelo auxílio-reclusão para apenas famílias em condições mais extremas de exclusão social de contribuintes da Previdência Social.

Gráfico 1 - Quantidade dos Auxílios-reclusão emitidos 1994-2008

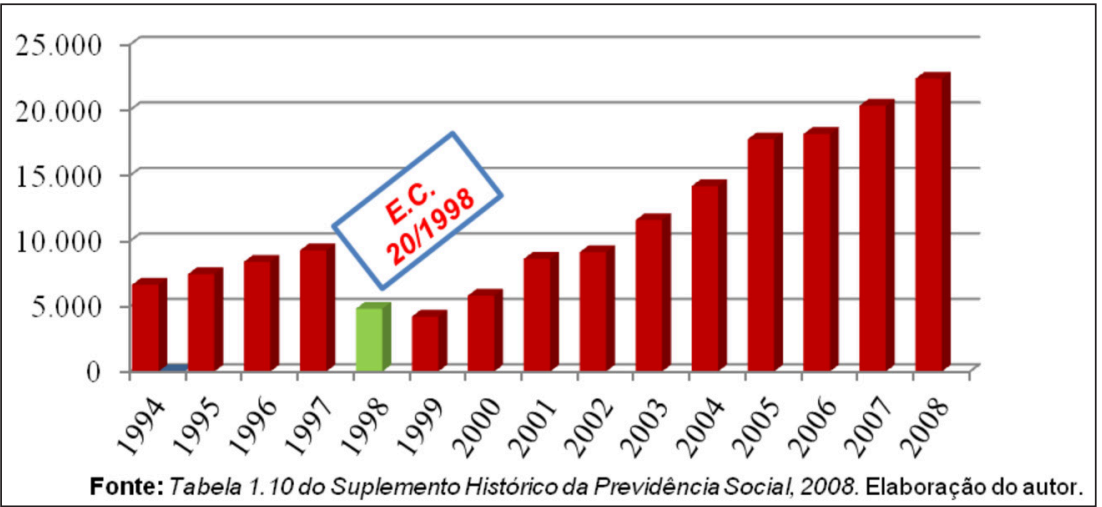


Gráfico 2 - Valor dos Auxílios-reclusão emitidos 1994-2008

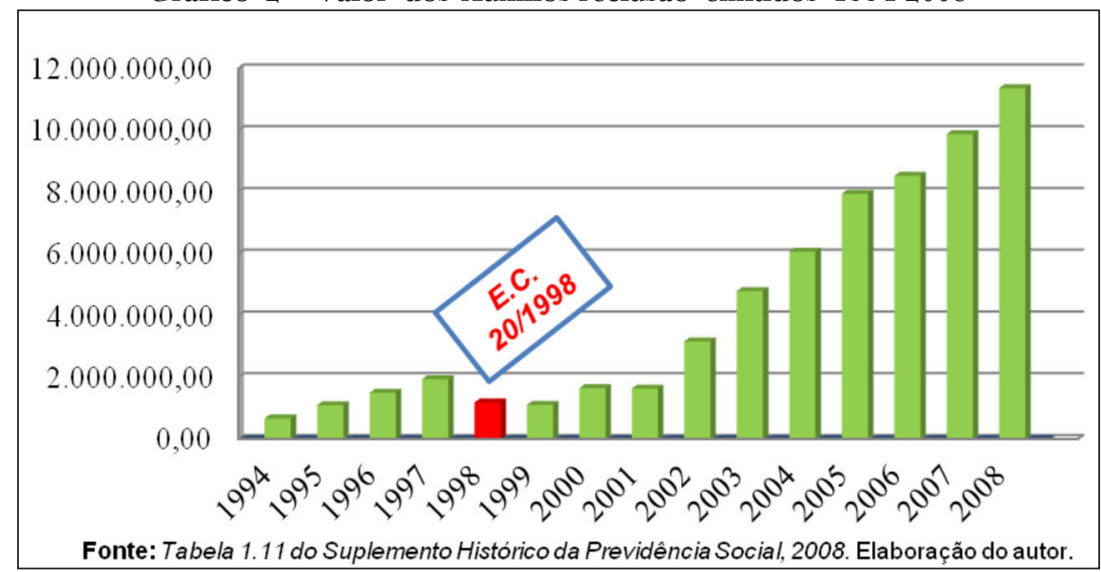

Em ambos os gráficos, fica nítido o recuo da tendência histórica da quantidade de benefícios emitidos já no primeiro momento posterior à edição da Emenda Constitucional n. 20 de 1998.

Naturalmente, quando a quantidade de benefícios diminui, também é de se esperar a redução do valor despendido com o auxílio-reclusão, conforme demonstra o gráfico 2.

Entretanto, apesar da inicial redução de concessões do benefício, o fenômeno do encarceramento em massa, agravado nos últimos anos, sobretudo em decorrência de ações do Executivo e do Judiciário, foi decisivo para o posterior aumento. Para se ter melhor ideia desse fenômeno no período, o gráfico 3 traz o aumento populacional durante o período de 2000 a 2008. Importa esclarecer, todavia, que o Departamento Penitenciário Nacional - DEPEN - não disponibiliza estatísticas anteriores a 2000. No censo penitenciário de dezembro de 2012, o número total de presos no país alcançou a cifra de 548.003. 


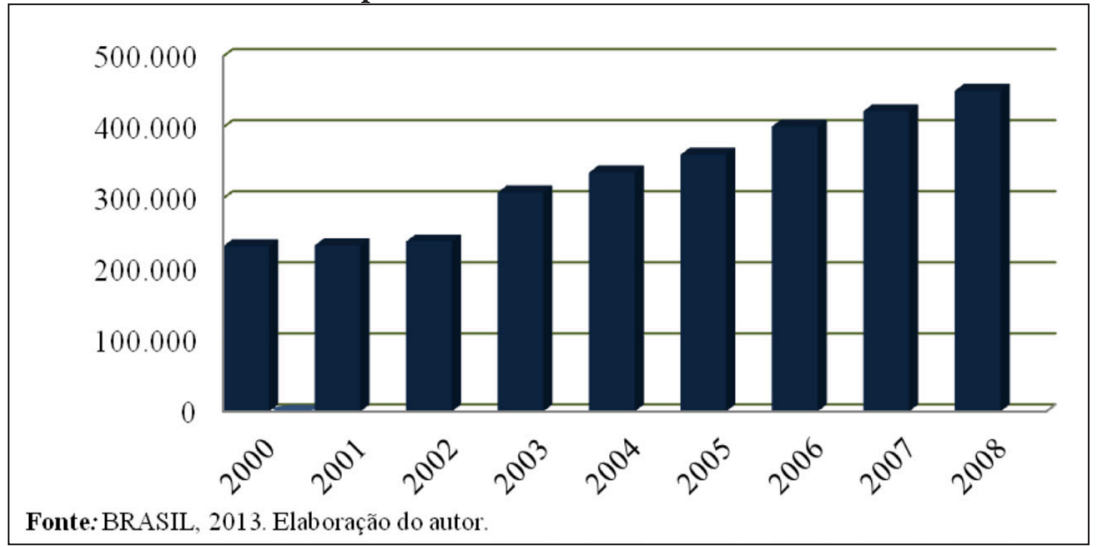

Observando mais atentamente os três gráficos apresentados, há uma nítida relação entre o aumento populacional e o aumento na emissão de auxílios-reclusão. No entanto, apenas uma minúscula parcela de familiares de pessoas presas é beneficiada, e a proporcionalidade dessa relação praticamente não sofre alteração ao longo dos anos.

O fato é que a concessão do benefício representa uma diminuta parcela no total dos gastos da Previdência. No ano de 2011, havia 43.124 benefícios dessa natureza ativos, foram concedidos 14.672 novos e 4.697 cessaram (BRASIL, 2011). Em 2011, a população nacional encarcerada era de 514.582 pessoas (BRASIL, s.d.3), significando que menos de um a cada cem presos fazia jus ao benefício. Tendo em conta que o total despendido com os benefícios de auxílio-reclusão emitidos era, em 2011, de $\mathrm{R} \$ 21.253 .000,00$, para 33.245 beneficiados, perfazia apenas $0,11 \%$ do total dos gastos da Previdência Social ${ }^{3}$.

Qualquer discussão racional sobre a ampliação ou a extinção do benefício não pode confundir o capital administrado pelo sistema previdenciário com aquele montante arrecadado pelo Estado através de seu poder geral de tributar. São recursos de naturezas distintas. No caso dos tributos, é dinheiro público que deve ser revertido para o benefício mais amplo da população, conforme diferentes estratégias políticas de gastos públicos

\footnotetext{
${ }^{3}$ Em 2011, o total de gastos ativos foi de $\mathrm{R} \$ 23.154 .879 .225,00$, segundo o Anuário Estatístico da Previdência Social (BRASIL, 2011).
} 
empreendidos pelos governos. No caso de recursos da Previdência, trata-se de recursos administrados pelo Estado, custeados por parcelas da população na qualidade de segurados, que visam resguardar esses contribuintes em caso de necessidade proveniente de algumas contingências sociais. É o caso do auxílio-reclusão.

Um dos requisitos principais para a concessão desse benefício é o vínculo da pessoa presa com o Instituto Nacional de Seguridade Social. Embora o número de trabalhadores com carteira assinada tenha aumentado demasiadamente na última década, o mercado de trabalho informal ainda é grande, e boa parte da população brasileira não preenche os critérios legais para o benefício previdenciário no momento de reclusão ${ }^{4}$. Essas exigências restringem a concessão desse benefício previdenciário para a parte considerável da população encarcerada e fazem com que o percentual de beneficiados seja bem reduzido. Além disso, o benefício cessa, mais cedo ou mais tarde. Os dependentes devem apresentar a cada três meses uma certidão atualizada da situação do parente preso e, nessas ocasiões, o benefício pode ser extinto ${ }^{5}$.

Mesmo pessoas que cumprem - em tese - os requisitos legais encontram diversas barreiras nos âmbitos administrativo e judicial para fazer jus efetivamente ao auxílio-reclusão. Dantas e Rodrigues (2009) mostram que o número de pedidos indeferidos é maior que o de concedidos. Como exemplo de motivos para o indeferimento, pode-se citar a dificuldade de se comprovar a dependência, o vínculo com a Previdência e o devido enquadramento dos requerentes na condição de baixa renda.

Um pressuposto legal para sua concessão é o de que a pessoa considerada autora de algum delito já esteja respondendo severamente mediante a

\footnotetext{
${ }^{4}$ Para saber mais, ver o trabalho do Departamento Intersindical de Estatística e Estudos Socioeconômicos- DIEESE - A situação do trabalho no Brasil na primeira década dos anos 2000 (2012).

${ }^{5}$ O Regulamento da Previdência Social (Decreto 3.048/1999) prevê hipóteses em que o benefício pode ser cassado: - com a morte do segurado e, nesse caso, o auxílio-reclusão será convertido em pensão por morte; - em caso de fuga, liberdade condicional, transferência para prisão albergue ou cumprimento da pena em regime aberto; - se o segurado passar a receber aposentadoria ou auxílio-doença (os dependentes e o segurado poderão optar pelo benefício mais vantajoso, mediante declaração escrita de ambas as partes); - ao dependente que perder a qualidade (ex: filho ou irmão que se emancipar ou completar 21 anos de idade, salvo se inválido; cessação da invalidez, no caso de dependente inválido, etc.); - com o fim da invalidez ou morte do dependente.
} 
privação de liberdade. Estar recluso em instituições prisionais no Brasil é, na maior parte das vezes, se submeter a condições degradantes, com agravantes diversos não previstos formalmente na sentença condenatória, como a superlotação, a insalubridade do ambiente, a violação a diversos direitos humanos, etc. ${ }^{6}$

As críticas à instituição prisional são antigas na literatura da sociologia da punição. Há prisões piores do que outras e, no Brasil, a situação predominante dos estabelecimentos é de calamidade, com a violação sistemática da maioria dos direitos previstos na Lei de Execução Penal7 Além de não servir a qualquer pretensão de integração social das pessoas privadas de liberdade, essa realidade degradante tende a acarretar muitos custos sociais para a sociedade, atingindo não apenas a pessoa presa, mas seus entes familiares e a sociedade como um todo. Baratta (2006b; p. 311) ressalta, a partir de resultados de pesquisa empírica realizada no Canadá em 1981, que os efeitos devastadores do cárcere são muito piores para as famílias mais pobres, tendendo a condená-las a uma situação inferior à da trajetória própria do grupo de origem.

O sistema prisional brasileiro está repleto de pessoas dos estratos sociais mais pobres e marginalizados economicamente da sociedade brasileira. Não se pode ignorar que, ao longo da história, os sistemas punitivos ocidentais - não apenas o brasileiro - guardam uma estreita relação com o sistema de produção vigente ${ }^{8}$ e, embora a prática de delitos esteja longe de ser um fenômeno restrito às camadas mais pobres da sociedade, os processos de criminalização ${ }^{9}$ costumam ser altamente seletivos quando tratam da

\footnotetext{
${ }^{6}$ Pode-se ver melhor sobre denúncias de violações de direitos humanos nas prisões brasileiras no recente relatório apresentado pelo Grupo de Trabalho sobre Detenção Arbitrária, do Conselho de Direitos Humanos da Organização das Nações Unidas (ONU), apresentado em junho de 2014 na Assembleia Geral da ONU e causando constrangimentos ao Governo brasileiro (ORGANIZAÇÃO DAS NAÇÕES UNIDAS, 2014).

${ }^{7}$ Sobre denúncias de violação de direitos nas prisões de São Paulo, ver Ferreira (2014).

${ }^{8}$ Para saber mais sobre o assunto, ver Rusche e Kirshheimer (2004) e Foucault (2003).

${ }^{9} \mathrm{O}$ que Alessandro Baratta (2006a) chamava de "processo de criminalização", referia-se aos diversos processos sociais que resultam na prisão de um indivíduo, desde a ação do legislador ao definir quais condutas merecerão maior reprobabilidade pela lei penal, passando pela ação prática dos órgãos de repressão, até a submissão do caso aos diversos filtros existentes na prática Judiciária.
} 
aplicação de penas de prisão ${ }^{10}$. Nesse sentido, o censo penitenciário de dezembro de 2012 (BRASIL, s.d.3) diagnosticou que 86\% (oitenta e seis por cento) dos cerca de 550 mil presos do país não possuíam nem sequer o ensino médio completo, número bem inferior à média nacional ${ }^{11}$. Os últimos anos registraram um aumento no acesso à educação e na escolaridade média do brasileiro, mas esses avanços parecem ter ficado distantes do sistema prisional $^{12}$.

Considerando-se essa realidade, pode-se presumir que o benefício previdenciário concedido para os dependentes de pessoas presas tende a fazer uma diferença significativa na vida dessas pessoas.

\section{Distintas Propostas de Emenda Constitucional referentes ao Auxílio-Reclusão}

Distintas propostas de emenda constitucional (PECs) referentes a reformas no auxílio-reclusão tramitaram no Congresso Nacional brasileiro nessa última Legislatura: a PEC n. 420/2009, a PEC n. 20/2011, a PEC n. 33/2013 e a PEC n. 304/2013, que tramita com a PEC n. 368/2013 em apenso.

A propositura das quatro PECs referidas deu-se conforme o disposto no inciso I, do artigo 60, da Constituição Federal, contando com as assinaturas de um terço, no mínimo, dos membros de uma das casas do Congresso.

A PEC n. 420/2009, de autoria do Deputado Ratinho Junior, do PSC/ PR, visa retirar o limite de renda para o pagamento do benefício imposto pela Emenda Constitucional n. 20, de 1998, retomando a situação prevista no texto da Constituição Federal de 1988. Na prática, excluiria um dos requisitos para a concessão do auxílio-reclusão e aumentaria um pouco o número de potenciais beneficiados. Contava, na época de sua propositura,

\footnotetext{
${ }^{10}$ Para saber mais sobre essa relação, ver Garland (2006) e Wacquant (2011).

${ }^{11}$ Para se ter uma ideia dos dados nacionais, na Pesquisa Nacional por Amostra de Domicílio PNAD - de 2009, promovida pelo Instituto Brasileiro de Geografia Estatística - IBGE -, 48\% dos jovens entre 18 a 24 anos não tinham o ensino médio completo (ACESSO ao ensino superior no Brasil: equidade e desigualdade social, 2012).

12 Estudo do Instituto de Pesquisas Econômicas Aplicadas - IPEA -, com base nos últimos PNADs, evidenciou um significativo aumento da escolaridade média do brasileiro nos últimos dez anos (BRASIL, 2013a).
} 
com as assinaturas confirmadas de 211 Deputados $^{13}$.

Como justificativas, argumentou-se que deveria prevalecer para o auxílioreclusão o mesmo princípio da pensão por morte, mantendo-se idênticos critérios de cálculo e concessão, por serem ambos voltados ao "amparo aos dependentes do segurado na sua falta permanente ou provisória”. Assim, serão protegidas as crianças e adolescentes, que correspondem, na maioria dos casos, aos dependentes do segurado. Termina refletindo que:

limitar a concessão do auxílio-reclusão ao valor do salário-decontribuição do segurado recluso ou à renda de seus dependentes mostra-se espúrio, por contrariar o princípio básico do seguro social de proteção aos dependentes do segurado exposto a risco social não programável cuja renda foi cessada. Essa proteção é feita mediante a concessão a esses dependentes de benefício de prestação continuada calculado com base no salário-de-contribuição do segurado, que não terá valor inferior ao salário mínimo e nem superior ao valor máximo de salário-de-contribuição.

Além disso, a adoção de seletividade na concessão do auxílioreclusão vem denotando, entre outras, as seguintes impropriedades:

- descaracterização de sua natureza de benefício previdenciário sujeito às regras do seguro contributivo obrigatório, ao submeter sua concessão a critérios da assistência social cujos benefícios independem de contribuição e são concedidos a pessoas de baixa renda ou nenhuma renda;

- discriminação e preconceito para com as pessoas de baixa renda, por induzir que apenas estas cometem crimes, são apenadas e recolhidas à prisão;

- punição aos segurados de renda superior ao patamar fixado que foram apenados e recolhidos à prisão, e, por consequência, a seus dependentes ${ }^{14}$.

Em 2011, o Deputado Federal Fernando Francischini (PSDB/PR) apresentou a PEC 30/2011, visando excluir a prestação do auxílio-reclusão

\footnotetext{
${ }^{13}$ Os Deputados Federais subscritores da PEC 420/2009 estão vinculados aos seguintes partidos: 44 do PMDB, 37 do PT, 18 do DEM, 15 do PR, 14 do PSDB, 14 do PSB, 11 do PP, 11 do PDT, 9 do PTB, 7 do PSC, 5 do PV, 5 do PCdoB, 3 do PPS, 2 do PTC, 2 do PRB, 2 do PMN e 1 do PSOL. ${ }^{14}$ Disponível em: http:/ /www.camara.gov.br/proposicoesWeb/prop_mostrarintegra?codteor=7 04342\&filename=PEC+420/2009. Acesso em 29 de julho de 2014.
} 
para dependentes de pessoas condenadas pela "prática de tortura, racismo, terrorismo, tráfico ilícito de entorpecentes e drogas afins, pedofilia e crimes definidos como hediondos"15. Como justificativa para essa proposta, o parlamentar apenas mencionou genericamente a existência de um entendimento na sociedade no sentido de limitar o auxílio-reclusão apenas aos dependentes de autores de crime de menor gravidade. A PEC também conta com dispositivo para impor ao Estado a criação de oportunidades de trabalho para as pessoas presas, inclusive para os não beneficiados pelo auxílio-reclusão, sendo que os presos que trabalharem terão obrigação de destinar a fração de 1/3 dos ganhos auferidos para ressarcimento do Estado pelas despesas com a sua manutenção no cárcere.

No calor das mobilizações populares de 2013, em 02 de julho de 2013 foi apresentada a PEC n. 33/2013 ${ }^{16}$, da autoria do Senador Alfredo Nascimento (PR/AM), visando extinguir o auxílio-reclusão ${ }^{17}$. Sua justificativa fez expressa referência à "conjuntura atual", referindo-se expressamente ao clamor da população:

Há muito se protesta, especialmente através de correntes de e-mails ou em redes sociais e, de um modo geral na mídia, contra o auxílio-reclusão. Os protestos enfurecidos atacam o brio dos brasileiros, dizem seguramente que os trabalhadores que contribuem com o Regime Geral da Previdência pagam a conta para que os dependentes do detento em regime fechado usufruam do benefício.

Por isso, o referido auxílio-reclusão é um benefício previdenciário que ainda gera muita polêmica. Para a sociedade não é fácil aceitar pacificamente a concessão do benefício àqueles que cometeram crimes, ainda que se leve em conta os aspectos e circunstâncias fáticas que resultaram na condenação somada ao comportamento prisional do detento que, invariavelmente, por natureza, é hostil quanto à aceitação e cumprimento da pena e, não raro, agravado

\footnotetext{
${ }^{15}$ Disponível em: http:/ / www.camara.gov.br/proposicoesWeb/prop_mostrarintegra?codteor=8 73634\&filename=PEC+30/2011 . Acesso em 29 de julho de 2014.

${ }^{16}$ Não confundir a PEC n. 33/2013 com a já famosa PEC n. 33/2011, que gerou grande celeuma em torno da suposta violação à separação de poderes que a eventual aprovação dessa emenda proporcionaria.

${ }^{17}$ Os senadores subscritores da PEC33/2013 estão vinculados aos seguintes partidos políticos: 12 do PMDB, 3 do DEM, 3 do PTB, 2 do PR, 2 do PDT, 2 do PSDB, 2 do PP, 1 do PSC e 1 do PRB.
} 
pela própria conduta no curso do internato (com participação em rebeliões e outras práticas criminosas no âmbito interno e repercussão externa do cárcere). Daí os questionamentos e a dificuldade de aceitação por parte da sociedade em concordar com esse tipo de benefício.

O auxílio-reclusão faz parte das garantias previdenciárias constantes no artigo 201 e incisos da Constituição Federal. Assim, para que se possa fazer reforma normativa sobre o tema, é necessária a aprovação de emenda constitucional, excluindo o auxílioreclusão do rol de garantias previdenciárias, além de desonerar a previdência social de um encargo que se mostra, pela conjuntura atual, indevido e injusto ${ }^{18}$.

A PEC n. 304/2013, por sua vez, foi apresentada perante a Câmara dos Deputados pela Deputada Federal Antonia Lucileia Cruz Ramos Câmara (PSC/AC), na data de 29 de agosto de 2013. Além de almejar o fim do auxílio-reclusão, propõe-se a instituição de um benefício previdenciário para as vítimas de crime para figurar no lugar do auxílio-reclusão, nos seguintes termos:

VI - a garantia de um salário mínimo de benefício mensal à pessoa vítima de crime, pelo período que for afastada da atividade que garanta seu sustento e, em caso de morte da vítima, conversão do benefício em pensão ao cônjuge ou companheiro e dependentes da vítima, na forma da lei ${ }^{19}$.

No final de 2013, a essa PEC foi apensada a PEC n. 368/2013, apresentada à Câmara dos Deputados, em 11 de dezembro de 2013, pelo Deputado Federal Fábio Faria, do Partido Social Democrático (PSD), que prevê a criação de um benefício assistencial em favor das vítimas de delitos e não trata diretamente do auxílio-reclusão.

\footnotetext{
${ }^{18}$ Disponível em: http://www.senado.gov.br/atividade/materia/detalhes.asp?p_cod_ mate=113456. Acesso em: 29 de julho de 2014 .

19 Disponível em: http://www.camara.gov.br/proposicoesWeb/prop_mostrarintegra;jsessioni $\mathrm{d}=$ E90403EFA48D81EF5E0BA451782E5899. proposicoesWeb1 codteor=1123340\&filename $=\mathrm{P}$ EC+304/2013. Acesso em 29 de julho de 2014.
} 
Tabela 1 - Resumo das PECs sobre auxílio-reclusão

(Legislatura 2011-2014).

\begin{tabular}{|c|c|c|c|}
\hline PECs & Autor & $\begin{array}{c}\text { Data de } \\
\text { apresentação }\end{array}$ & Síntese da Proposta \\
\hline $420 / 2009$ & $\begin{array}{l}\text { Dep. Fed. Ratinho } \\
\text { Junior (PSC/PR) }\end{array}$ & 20.10 .2009 & $\begin{array}{l}\text { Retira o limite de renda para } \\
\text { o pagamento do benefício } \\
\text { imposto pela Emenda } \\
\text { Constitucional n. 20, de } \\
\text { 1998, ampliando o público } \\
\text { beneficiado. }\end{array}$ \\
\hline $30 / 2011$ & $\begin{array}{l}\text { Dep. Fed. } \\
\text { Fernando } \\
\text { Francischini } \\
(\text { PSDB/PR) }\end{array}$ & 18.05 .2011 & $\begin{array}{c}\text { Veda o auxílio-reclusão para } \\
\text { segurados que respondam } \\
\text { por crimes graves e impõe } \\
\text { ao Estado a criação de } \\
\text { oportunidades de trabalho } \\
\text { para as pessoas presas, } \\
\text { destinando-se parte do salário } \\
\text { para pagar despesas com o } \\
\text { recluso. }\end{array}$ \\
\hline $33 / 2013$ & $\begin{array}{l}\text { Sen. Fed. Alfredo } \\
\text { Nascimento (PR/ } \\
\text { AM) }\end{array}$ & 02.07 .2013 & Extingue o auxílio-reclusão. \\
\hline $304 / 2013$ & $\begin{array}{l}\text { Dep. Fed. Antonia } \\
\text { Lucileia Cruz } \\
\text { Ramos Câmara } \\
\text { (PSC/AC) }\end{array}$ & 29.08.2013 & $\begin{array}{l}\text { Extingue o auxílio-reclusão. A } \\
\text { PEC } 368 / 2013 \text {, que tramita em } \\
\text { apenso, prevê a instituição de } \\
\text { um benefício previdenciário } \\
\text { para as vítimas de crime. }\end{array}$ \\
\hline
\end{tabular}

Fonte: Páginas eletrônicas do Senado Federal e da Câmara dos Deputados. Elaborada pelo autor.

É adequado que as vítimas de crimes recebam alguma forma de reparação pelo delito. Já existem no ordenamento brasileiro benefícios que cumprem a função prevista nas propostas de emenda, como é o caso da pensão por morte e do auxílio-invalidez. O Código de Processo Penal impõe ao juiz a fixação de reparação de danos da vítima, quando da sentença criminal condenatória ${ }^{20}$. Além disso, sempre existe a possibilidade de ingresso de ação reparatória na esfera cível. Não há nenhuma incompatibilidade entre um benefício assistencial ou previdenciário para vítimas diretas de delitos e o

\footnotetext{
${ }^{20}$ A redação do inciso IV, do artigo 387, fixada pela lei 11.719/2008, prevê que o juiz, quando da fixação da pena, "fixará valor mínimo para reparação dos danos causados pela infração, considerando os prejuízos sofridos pelo ofendido".
} 
auxílio-reclusão. Os dois benefícios podem conviver simultaneamente. Um não precisa ser suprimido para que o outro exista.

Por outro lado, não se pode ignorar que costumam sofrer danos do ato criminoso, mesmo que de forma indireta, também os familiares das pessoas privadas de liberdade. O delito provoca - muitas vezes - uma desestruturação na dinâmica das famílias, afetando-as de forma afetiva, econômica e até influenciando em aspectos morais e educacionais. Quando a família não abandona a pessoa presa - algo que ocorre muitas vezes -, os seus membros passam a se submeter a muitos sacrifícios para visitar o ente e para providenciar bens de primeira necessidade que o Estado não costuma fornecer ${ }^{21}$.

As justificativas oficiais desses dois projetos exploram o desamparo das vítimas da violência, mas a da PEC n. 304/2013 traz vários ataques ao auxílioreclusão, afirmando, por exemplo, que o auxílio-reclusão constitui um estímulo para a decisão do cometimento de um delito e que "é mais justo "amparar a família da vítima do que a do criminoso"22.

$\mathrm{O}$ andamento de todas essas propostas no Congresso será discutido a seguir.

\section{A Tramitação das PECs e o Novo Cenário Político}

Uma mudança no sentido de se extinguir o auxílio-reclusão tende a ser mais respaldada pelos partidos mais à direita no espectro político-ideológico.

Ao menos desde a campanha empreendida contra os direitos de pessoas presas durante os anos 1980, cujos embates foram bem relatados por Caldeira $(2000)^{23}$, os setores políticos mais conservadores e a direita política,

${ }^{21}$ Para mais informações sobre as dificuldades enfrentadas por famílias de pessoas presas, ver Godoy (2014).

${ }^{22}$ Disponível em: http://www.camara.gov.br/proposicoesWeb/prop_mostrarintegra;jsessioni d=E90403EFA48D81EF5E0BA451782E5899. proposicoesWeb1? codteor=1123340\&filename=P EC+304/2013. Acesso em: 29 de julho de 2014.

${ }^{23}$ Caldeira (2000) mostra como foi forte o movimento contra os direitos humanos de pessoas presas em oposição às iniciativas do Governo Montoro (1983-1987), que seguiam no sentido de "humanização" das condições de vida no cárcere. Foi protagonizado por políticos de direita, por setores da polícia do Estado de São Paulo e por expoentes da imprensa. 
no sentido comportamental, estão fortemente ligados a uma perspectiva de punição, que passa pelo sofrimento do acusado ou condenado e pela vingança. Por outro lado, os grupos mais identificados com uma visão de defesa da lei, de direitos, da justiça e do sistema judiciário reúnem expoentes do centro e da esquerda política, passando por intelectuais, setores da Igreja Católica e diversas associações civis.

É sintomático a Emenda Constitucional n. 20/1998 - que restringiu bastante o público atendido pelo auxílio-reclusão, quando foi imposto um critério de renda -, ter sido aprovada logo na Legislatura em que a Câmara dos Deputados teve uma das configurações mais conservadoras das últimas décadas. Conforme a pesquisa de Santos, Canello e Cunha (2014b), a Câmara dos Deputados contava em 1998 com um bloco de direita de nada menos que $60,4 \%$ da Casa.

No entanto, apesar de a ampliação do público beneficiado pelo auxílioreclusão ser uma pauta que parece se identificar mais com o espectro políticoideológico da esquerda comportamental, o autor da PEC n. 420/2009 Ratinho Júnior (PSC/PR) - pertence a um partido considerado de direita. $\mathrm{Na}$ lista de assinaturas que viabilizou a propositura da PEC, verifica-se um flagrante equilíbrio entre representantes da esquerda, do centro e da direita, com, respectivamente, $33.8 \%$, 35,85\% e $30.3 \%{ }^{24}$.

No caso da PEC n. 30/2011, que restringe o benefício para beneficiados acusados da prática de crimes mais graves, apesar de haver apoio significativo por parte de representantes de partidos da esquerda e do centro - com $30,68 \%$ e $31,82 \%$, respectivamente -, a maioria das assinaturas foi obtida por

\footnotetext{
${ }^{24}$ Os cálculos tomam por base as 198 assinaturas confirmadas de Deputados Federais do Relatório de Conferência de Assinaturas da PEC n .420/2009, elaborado em de 22.10.2009 (Disponível em: http://www.camara.gov.br/proposicoesWeb/prop_mostrarintegra;jsessionid $=$ B6F4C3FF368AB332505EF50E20088E41 .proposicoesWeb2 codteor $=705773 \&$ \&ilename $=$ Tram itacao-PEC+420/2009 . Acesso em 23 de novembro de 2014) e o critério de distribuição de partidos no espectro político ideológico proposto pelos estudiosos do Núcleo de Estudos sobre o Congresso (NECON), vinculado ao Instituto de Estudos Sociais e Políticos da Universidade do Estado do Rio de Janeiro (SANTOS; CANELLO; CUNHA, 2014b). Assim, no centro, foram incluídos o PMDB, o PROS, o PRB, o PR, o PSD, o SD, o PV, o PEN, o PTC, o PMN, o PSL, o PRP e o PHS; à direita, foram considerados o DEM, o PSDB, o PPS, o PP, o PTB, o PSC, o PT do B, o PTN, o PRTB e o PSDC; à esquerda foram elencados o PT, o PC do B, o PDT, o PSB e o PSOL.
} 
parlamentares considerados de bancadas de direita - com 37,5\% ${ }^{25}$. Trata-se de um projeto que interfere no benefício de modo menos radical do que os outros mais recentes, afetando apenas um pequeno número de segurados - e familiares - acusados e condenados por delitos que causam maior comoção.

No total das assinaturas que permitiram a propositura da PEC n. 33/2013, que visa extinguir o auxílio-reclusão, percebe-se nitidamente a prevalência de representantes de partidos do centro e da direita, com 55,17\% e 37,03\%, respectivamente ${ }^{26}$.

Na propositura da PEC n.304/2013, a maioria das assinaturas também provém de partidos políticos do centro e da direita, com a idêntica porcentagem de $36,6 \%$ cada $\mathrm{um}^{27}$.

${ }^{25}$ Os cálculos tomam por base as 176 assinaturas confirmadas de Deputados Federais do Relatório de Conferência de Assinaturas da PEC n. 30/2011, elaborado em 20 de abril de 2011 (Disponível em: file:///C:/Users/Ot\%C3\%A1vio/Dropbox/Escritos\%20diversos/Artigos\%20 acad\%C3\%AAmicos\% 20Ci\% C3\%AAncias\% 20Sociais/Auxilio\% 20reclus\%C3\%A3o/ Subscri\%C3\%A7\%C3\%B5es\%20da\%20PEC\%2030-2011.pdf. Acesso em 23 de novembro de 2014) e o critério de distribuição de partidos no espectro político ideológico proposto pelos estudiosos do NECON (SANTOS; CANELLO; CUNHA, 2014b).

${ }^{26}$ Os cálculos tomam por base as 29 assinaturas de Senadores disposta na página eletrônica do Senado Federal (Disponível em: http://www.senado.gov.br/atividade/materia/detalhes.asp?p_ cod_mate=113456. Acesso em 24 de novembro de 2014). Adota-se o critério de distribuição de partidos no espectro político ideológico proposto pelos estudiosos do NECON (SANTOS; CANELLO; CUNHA, 2014b).

${ }^{27}$ Os cálculos tomam por base as 172 assinaturas confirmadas de Deputados Federais do Relatório de Conferência de Assinaturas da PEC n. 30/2011, elaborado em 20.05.2011 (Disponível em: http:/ / www.camara.gov.br/proposicoesWeb/prop_mostrarintegra?codteor=1127331\&filenam e=Tramitacao-PEC+304/2013 . Acesso em 23 de novembro de 2014) e o critério de distribuição de partidos no espectro político ideológico proposto pelos estudiosos do NECON (SANTOS; CANELLO; CUNHA, 2014b). 

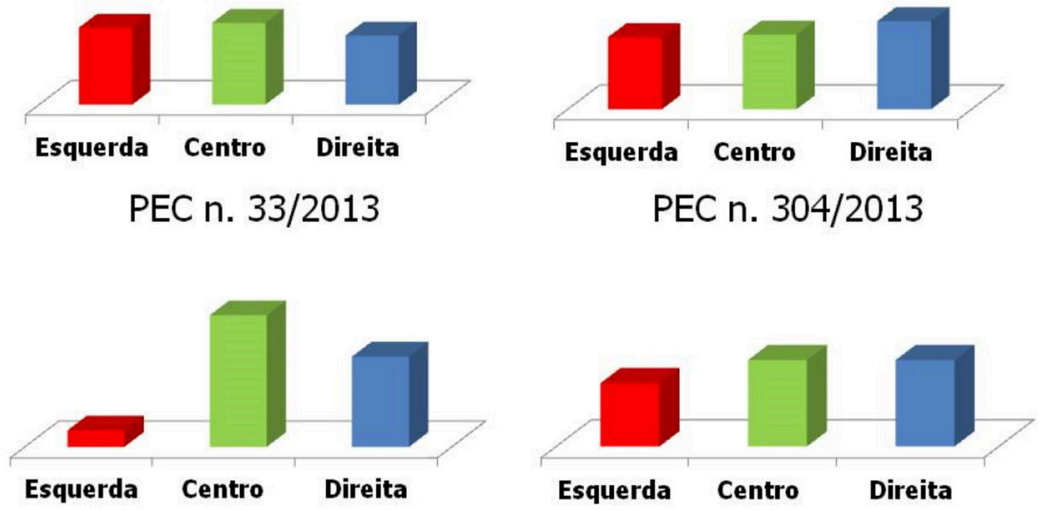

Fonte: Páginas eletrônicas do Senado Federal e da Câmara dos Deputados. Elaboração do autor.

Observando-se o gráfico 4, que compara as assinaturas das proposições das 4 PECs, nota-se uma participação maior de partidos da direita nas duas PECs mais recentes, que pretendem acabar com o benefício previdenciário. Nas outras duas, há maior equilíbrio, havendo até um número maior de assinaturas de partidos da esquerda no projeto mais antigo, que almeja a ampliação do público de segurados do auxílio-reclusão. As bancadas dos partidos do centro aparecem com destaque na proposição das quatro PECs.

As 4 PECs, cujos conteúdos são distintos entre si, e até contraditórios, obtiveram - em casas distintas - de um mesmo partido - o PMDB -, a maioria das assinaturas que ensejaram as suas proposituras, nos termos do inciso I, do artigo 60, da Constituição Federal. Essa constatação parece reafirmar a heterogeneidade desse partido político identificado com o centro no espectro político-ideológico, que costuma eleger numerosas bancadas no Congresso.

Vale ponderar que a convicção e os critérios norteadores de uma decisão de assinatura em uma proposição de lei ou de emenda constitucional tendem a ser menos rigorosos do que aqueles utilizados para a decisão sobre sua aprovação, no final da tramitação. O parlamentar age com maior liberdade nas etapas preliminares do processo legislativo, sem tanta pressão da liderança partidária - e do Executivo -, do que nos seus momentos 
derradeiros, quando se esperam maior coesão e fidelidade ${ }^{28}$.

O trâmite de aprovação de uma proposta de emenda constitucional (PEC), mesmo no caso de não enfrentar nenhuma alteração do texto, é complexo ${ }^{29}$. Depois de apresentada a PEC nos termos do artigo 60 da Constituição Federal, sua admissibilidade é avaliada no âmbito da Comissão de Justiça e Cidadania da Câmara dos Deputados. Caso seja aprovada ali, designa-se uma comissão especial para a análise do conteúdo da PEC. A Comissão Especial vai produzir um parecer que vai se prestar como orientação para a votação da proposta no Plenário da casa legislativa. Aprovada pelo quórum de 3/5 dos deputados em dois turnos, ela segue para o Senado. Lá, também é submetida à análise da Comissão de Constituição e Justiça e Cidadania, de onde segue para o Plenário, onde deve obter a aprovação por maioria qualificada em dois turnos.

Ao final de uma Legislatura, porém, de acordo com o artigo n. 105 do Regimento Internos da Câmara dos Deputados (RICD) ${ }^{30}$ e com o artigo n. 332 do Regimento Interno do Senado Federal (RISF) ${ }^{31}$, a regra é que as

\footnotetext{
${ }^{28}$ Sobre a fidelidade partidária, ver estudos de Figueiredo e Limongi (2000).

29 A depender de uma alteração no texto da PEC, o trâmite do processo legislativo deve ser retomado, e a proposta deve ser submetida novamente a todo o percurso.

${ }^{30}$ Conforme o artigo n. 105 do RICD: "Finda a legislatura, arquivar-se-ão todas as proposições que no seu decurso tenham sido submetidas à deliberação da Câmara e ainda se encontrem em tramitação, bem como as que abram crédito suplementar, com pareceres ou sem eles, salvo as: I - com pareceres favoráveis de todas as Comissões; II - já aprovadas em turno único, em primeiro ou segundo turno;

III - que tenham tramitado pelo Senado, ou dele originárias; IV - de iniciativa popular; V - de iniciativa de outro Poder ou do Procurador-Geral da República. Parágrafo único. A proposição poderá ser desarquivada mediante requerimento do Autor, ou Autores, dentro dos primeiros cento e oitenta dias da primeira sessão legislativa ordinária da legislatura subsequente, retomando a tramitação desde o estágio em que se encontrava".

${ }^{31}$ De acordo com o artigo n. 332 do RISF: "Ao final da legislatura serão arquivadas todas as proposições em tramitação no Senado, exceto: I - as originárias da Câmara ou por ela revisadas; II - as de autoria de Senadores que permaneçam no exercício de mandato ou que tenham sido reeleitos; III - as apresentadas por Senadores no último ano de mandato; IV - as com parecer favorável das comissões; $\mathrm{V}$ - as que tratem de matéria de competência exclusiva do Congresso Nacional (Const., art. 49); VI - as que tratem de matéria de competência privativa do Senado Federal (Const., art. 52); VII - pedido de sustação de processo contra Senador em andamento no Supremo Tribunal Federal (Const., art. 53, §§ 3o e 4o, EC no 35/2001). § 1 o Em qualquer das hipóteses dos incisos do caput, será automaticamente arquivada a proposição que se encontre em tramitação há duas legislaturas, salvo se requerida a continuidade de sua tramitação por 1/3 (um terço) dos Senadores, até 60 (sessenta) dias após o início da primeira sessão legislativa da legislatura seguinte ao arquivamento, e aprovado o seu desarquivamento pelo Plenário do Senado. § 2o Na hipótese do § 1o, se a proposição desarquivada não tiver a sua tramitação concluída, nessa legislatura, será, ao final dela, arquivada definitivamente”.
} 
PECs sejam arquivadas, salvo em determinadas situações.

Como o momento é de transição de Legislaturas, convém observar o estágio de tramitação de cada um dos projetos que tramitaram no período entre 2010 e 2014 para entender as possibilidades de desarquivamento.

A PEC n. 420/2009 é a mais antiga. Foi proposta durante a Legislatura de 2006-2010, e desarquivada no início da última Legislatura. Em 31.05.2011, o Relator Silas Câmara (PSD/AM) proferiu seu parecer pela admissibilidade do projeto na Comissão de Constituição e Justiça da Câmara dos Deputados. Esse parecer, entretanto, trata apenas do voto do relator e não da opinião dos demais membros do colegiado. Desde então, a proposta não teve novo andamento.

Pelo seu andamento processual, essa PEC não se enquadra nas exceções e está fadada ao arquivamento. Diferentemente do RISF, o RICD não veda expressamente o seu desarquivamento por mais de uma vez. Mas o texto da norma incumbe ao autor - ou aos autores - essa ação de desarquivamento e, no caso, o autor dessa PEC não é mais Deputado Federal ${ }^{32}$. Assim, essa PEC permanecerá arquivada de forma definitiva.

A PEC n. 30/2011, proposta pelo Deputado Federal Fernando Francischini (PSDB/PR), que trata da redução do alcance do benefício do auxílio-reclusão para os segurados acusados e condenados pela prática de alguns crimes considerados de maior gravidade e almeja obrigar o Estado a aumentar a oportunidade de trabalho para todas as pessoas presas, obrigandoas a destinarem parte dos salários para ressarcir o Estado por gastos com a sua prisão, ficou mais de dois anos parada na Comissão de Constituição, Justiça e Cidadania aguardando a designação de relatoria. Em 30.08.2013, o relator - o Deputado Mendonça Prado (DEM/SE) - expediu parecer, opinando pela sua admissibilidade. Até o final da Legislatura, os demais membros da Comissão não se pronunciaram. Está facultado ao autor, Delegado licenciado da Polícia Federal reeleito para a Câmara dos Deputados, agora membro da bancada do partido Solidariedade, o desarquivamento da PEC na nova Legislatura.

A PEC n. 33/2013 começou sua tramitação pelo Senado e encontra-se desde 05.05.2014 com o Relator - o Senador José Pimentel (PT/CE) - na

\footnotetext{
${ }^{32}$ Ratinho Júnior (PSC/PR), o autor da PEC n. 420/2009, foi eleito em 2014 para o cargo de Deputado Estadual na Assembleia Legislativa do Paraná.
} 
Comissão de Constituição e Justiça e Cidadania, aguardando relatório. Com o final da Legislatura, ela é automaticamente arquivada. Como o RISF não incumbe apenas ao autor - ou aos autores - da PEC o seu desarquivamento, sua tramitação poderá ser retomada na nova Legislatura.

A PEC n. 304/2013 segue com a PEC n. 368/2013 em apenso. Sua tramitação não avançou para além do parecer favorável à sua admissibilidade por parte do seu relator, o Deputado André Moura (PSC/SE), na Comissão de Constituição, Justiça e Cidadania em 18 de dezembro de $2013^{33}$.

Ao final de 2014, as duas PECs que tramitam juntas serão automaticamente arquivadas, podendo ser retomadas na nova Legislatura por iniciativa de seu autor - ou autores. No caso da PEC n. 304/2013, a autora Antonia Lúcia (PSC/AC) não foi reeleita, mas figura como suplente e tem alguma chance de assumir o cargo, hipótese em que a proposta poderá ser desarquivada, desde que isso ocorra nos primeiros 180 dias da nova Legislatura. No caso da PEC n. 368/2013, o Relator Fábio Faria (PSD/RN) foi reeleito e pode retomar a tramitação da proposta no início da nova Legislatura.

Os autores das duas PECs apresentadas em 2013 tentaram se aproveitar do momento de turbulência política causada pelas manifestações de junho de 2013. A PEC n. 33/2013, por exemplo, mencionou em suas justificativas expressamente a "conjuntura atual".

As chamadas Jornadas de Junho correspondem a um fenômeno complexo que foi objeto de distintas interpretações. Em um primeiro momento, as primeiras mobilizações populares de junho de 2013 em várias cidades do Brasil foram organizadas por movimentos sociais e de estudantes e tinham relação com o valor do transporte público municipal. Sofreram ofensivas por setores da mídia e dura repressão por parte das agências de segurança, sobretudo na capital paulista. No segundo momento, por motivações diversas, ampliouse enormemente o número de manifestantes, de movimentos participantes e de pautas reivindicatórias. Setores da mídia que tinham sido contrários aos primeiros protestos passaram a ser simpáticos às manifestações, mas destacaram seletivamente algumas pautas em detrimento de outras, como - por exemplo - a corrupção do Governo Federal (AVRITZER, 2013) e a degeneração da classe política (LIMONGI, 2013). A falta de infraestrutura

\footnotetext{
${ }^{33}$ Da mesma forma como exposto no caso da PEC n. 420.2009, vale dizer que este parecer não é vinculante para o resto do colegiado.
} 
urbana no Brasil, que estava na origem das manifestações, deixou de receber a luz dos maiores holofotes, e a extinção do auxílio-reclusão figurou como mais uma entre as múltiplas demandas mobilizadas pelos manifestantes.

A desconfiança da população em relação ao Congresso Nacional, segundo avaliação do Datafolha realizada em julho de 2013, aumentou nove pontos percentuais após a onda de protestos de junho (REPROVAÇÃO ao congresso sobe nove pontos depois de protesto, 2013). Como resultado direto, os deputados e senadores se preocuparam em apresentar para a população mais esforços na atividade parlamentar, e a produção legislativa foi intensificada no período imediatamente subsequente. Em comparação da produção legislativa no período de junho e julho, constatou-se um aumento de projetos aprovados, tanto na Câmara, quanto no Senado (APÓS os protestos, Congresso produz mais e prioriza projetos sociais, 2013. EM RESPOSTA às manifestações, legislativo acelera aprovação de projetos, 2013). Falou-se muito, nos discursos, sobre a necessidade de se dar uma urgente resposta ao "clamor popular das ruas". A referência a essa conjuntura política foi utilizada estrategicamente na tentativa de aprovação de projetos de maneira mais célere, à custa da mitigação dos debates.

Passado esse momento mais turbulento que afetou a rotina do Congresso Nacional, nenhuma das citadas PECs referentes ao auxílio-reclusão foi adiante no processo legislativo. A Legislatura chega ao fim, e as propostas de reforma do benefício previdenciário seguem para o arquivamento.

As eleições de 2014 garantiram a vitória de Dilma Roussef, mas o desenho das bancadas do Congresso sofreu alterações.

$\mathrm{Na}$ análise das mudanças nas bancadas partidárias nas últimas eleições para o Legislativo, realizada pelos pesquisadores Santos, Canello e Cunha (2014a), no âmbito do Núcleo de Estudos sobre o Congresso (NECON), destacam-se algumas constatações, como o aumento da fragmentação partidária, de 22 para 28 partidos com representação no Congresso Nacional; e uma pequena redução da base do Governo na Câmara dos Deputados (de $66,2 \%$ para $59,1 \%$ ) e um pequeno incremento dela no Senado (de $64,1 \%$ para $65,3 \%)$. Um reduzido fortalecimento da oposição no Congresso em relação à última eleição pode ser observado, retomando uma configuração semelhante à verificada em 2010.

Qualquer iniciativa que vise reformar auxílio-reclusão terá de ser negociada nessa nova correlação de forças. No estudo sobre o perfil ideológico dos parlamentares, esses mesmos pesquisadores ressaltam o grande equilíbrio das bancadas de Direita e de Esquerda, com uma prevalência de um bloco 
de Centro na nova configuração política do Congresso Nacional. Houve um fortalecimento pequeno da Direita na Câmara dos Deputados, mas não no Senado Federal. Ao contrário do que foi alardeado por alguns meios de comunicação, o avanço conservador não foi tão significativo. A análise comparativa do perfil de congressistas no longo prazo mostra o estancamento de uma tendência histórica de enfraquecimento da direita (SANTOS; CANELLO; CUNHA, 2014b).

Pesquisadores do NECON constataram na Legislatura recém-eleita um grande equilíbrio entre as bancadas com relação ao perfil político ideológico dos representantes: os partidos mais identificados com a direita na Legislatura recém-eleita conquistam 32,5\% das cadeiras da Câmara dos Deputados e $30,85 \%$, do Senado Federal; a esquerda conta com 26,8\% da Câmara dos Deputados e 33,33\% do Senado; enquanto o centro ocupa 30,8\% da Câmara e 35,79\% do Senado. (SANTOS; CANELLO; CUNHA, 2014b).

A mudança em relação à última Legislatura não é tão drástica. Há um equilíbrio de forças, e o bloco de partidos que integram o Centro, somados ao PMDB, serão decisivos no jogo político.

Nesse cenário equitativo de distribuição de forças políticas no campo ideológico e de dificuldades adicionais para formação de uma coalizão majoritária, parece mais improvável que medidas polêmicas que não sejam consideradas prioritárias para o Executivo ${ }^{34}$ e para as lideranças dos principais partidos tenham êxito no processo legislativo. Quando não há um significativo arranjo de forças, é mais provável que o projeto nem sequer siga adiante nos trâmites processuais.

A coligação liderada pelo Partido dos Trabalhadores buscará a construção e a gestão de uma coalizão majoritária no Congresso capaz de viabilizar a aprovação de projetos prioritários.

Destaca-se que a base do Governo recém-eleita para a Câmara dos Deputados - com 59.1\% -, ainda que votasse de maneira disciplinada,

\footnotetext{
${ }^{34}$ Estudos sobre o desenho institucional brasileiro pós-Constituição de 1988 apontam para um ambiente de estabilidade institucional, com a tendência de prevalência do Executivo Federal sobre o Legislativo, mediante alguns mecanismos constitucionais e regimentais e a formação - e manutenção - de gabinetes de coalizão em um ambiente multipartidário fragmentado (PALERMO, 2000; LIMONGI, 2006). Figueiredo e Limongi (2000) destacaram alguns arranjos institucionais que possibilitam o controle por parte do Executivo e das lideranças partidárias sobre o processo decisório das duas casas do Congresso e sobre a agenda dos trabalhos legislativos.
} 
tem um número de parlamentares insuficiente para alcançar a maioria qualificada para a aprovação de uma PEC (de 60\%), um entrave que não ocorre no Senado.

Considerando-se que a coligação que detém o poder no Governo Federal está à esquerda no espectro político e que no ambiente de coalizão ela costuma exercer uma significativa influência na agenda de trabalhos do Congresso, pode-se estimar uma maior improbabilidade de aprovação de reformas legislativas tendentes a abolir direitos e garantias fundamentais e, mais especificamente, um benefício como o auxílio-reclusão.

\section{Considerações Finais}

O auxílio-reclusão corresponde a um benefício de importância ínfima para o orçamento da Previdência Social, mas significativo para famílias de baixa renda, atenuando a situação de miséria enfrentada por muitas mulheres e crianças.

Pelo simples fato de ser um direito relacionado - ainda que indiretamente - a pessoas presas, está fadado a ser recebido com reservas por amplos setores da população. O funcionamento do auxílio-reclusão parece mal compreendido, e as campanhas mobilizadas pela sua extinção servem-se, muitas vezes, de informações e argumentos deturpados ou inverídicos.

Há de se convir que o próprio nome "auxílio-reclusão" parece impreciso e inadequado para traduzir o seu conteúdo, abrindo margem para algumas confusões conceituais.

Quando a justificação da PEC n. 33/2013 - que pretende extinguir o benefício - apela aos "protestos enfurecidos" que ofendem "o brio dos brasileiros", parece jogar com recursos retóricos e apelativos, furtando-se a uma densa discussão acerca de uma temática complexa. Um momento de turbulência política pode servir a favor ou contra a política, suprimindo ou estimulando o debate e o enfrentamento de ideias. Pode servir a pautas de direita ou de esquerda, pois, se há um clamor popular em torno da redução da idade penal e do fim do auxílio-reclusão, há também outros pleitos nas ruas de grande intensidade em favor da mobilidade urbana e pela mitigação de desigualdades sociais. O princípio majoritário parece tencionar valores basilares constitucionais e os fundamentos do Estado de direito, suscitando relevantes questões jurídicas e políticas.

Há diferentes propostas relacionadas ao auxílio-reclusão no Congresso 
Nacional, seja para ampliar o público atendido seja para extinguir o benefício previdenciário. Todas elas têm permanecido inertes ao longo dos últimos anos, não passando sequer pela decisão de admissibilidade na Comissão de Constituição e Justiça da casa onde o processo legislativo se iniciou.

Pelas análises sobre a nova configuração política desenhada pelas eleições de 2014, não parece que as correlações de forças tenham se alterado de modo significativo para um ou outro lado. Desse modo, em um cenário de grande equilíbrio de poder entre a esquerda, a direita e o centro nas casas legislativas e com a manutenção da Presidente Dilma Roussef no Executivo, não parece provável nem a aprovação de uma proposta para extinguir e nem para ampliar o auxílio-reclusão no curso desse novo período.

\section{Referências}

APÓS os protestos, Congresso produz mais e prioriza projetos sociais.

(2013). Portal G1. Rio de Janeiro: Globo, 07 de julho de 2013. Disponível em: http:// g1.globo.com/politica/noticia/2013/07/ apos-protestos-congresso-produz-mais-eprioriza-projetos-sociais.html. Acesso em 11 de setembro de 2013.

AVRITZER, Leonardo.

(2013). 0 que as manifestações no Brasil nos dizem?. Carta Capital. São Paulo, ed. Confiança, 18 de junho de 2013. Disponível em: http://www.cartacapital.com.br/ sociedade/o-que-as-manifestacoes-nobrasil-nos-dizem-1313.html. Acesso em 01 de setembro de 2013.

BARATTA, Alessandro.

(2006a). Observaciones sobre las funciones de la cárcel en la producción de las relaciones sociales de desigualdad. In: Alessandro Baratta; (compilación in memoriam); Carlos Alberto Elbert (Org.); Criminología y sistema penal. Buenos Aires: Editorial IBdeF; Júlio César Faira editor.

(2006b). Principios del derecho penal mínimo (para una teoría de los derechos humanos como objeto y limite de la ley penal). In: Alessandro Baratta; (compilación in memoriam); Carlos Alberto Elbert (Org.);
Criminología y sistema penal. Buenos Aires: Editorial IBdeF; Júlio César Faira editor.

MINISTÉRIO DA PREVIDÊNCIA SOCIAL. (2013b). Agência Eletrônica: auxílio-reclusão. Brasília, MPS. Disponível em: http://www. previdencia.gov.br/conteudoDinamico. php?id=22. Acesso em 01 de setembro de 2013.

(2011). Anuário Estatístico da Previdência Social. Brasília, MPS. Disponível em: http://www.previdencia.gov.br/arquivos/ office/1_121023-162858-947.pdf. Acesso em 01 de setembro de 2013.

(2008). Suplemento Histórico da Previdência Social. Brasília, MPS. Disponível em: http:// www.mpas.gov.br/conteudoDinamico. php?id=423. Acesso em 16 de setembro de 2013. BRASIL.

INSTITUTO BRASILEIRO DE GEOGRAFIA E ESTATÍSTICA; MINISTÉRIO DE PLANEJAMENTO, ORÇAMENTO E GESTÃO.

(2010). Censo Demográfico. Brasília: IBGE. Disponivel em: ftp://ftp.ibge.gov.br/Censos/ Censo_Demografico_2010/Caracteristicas_ Gerais_Religiao_Deficiencia/caracteristicas_ religiao_deficiencia.pdf. Acesso em 10 de outubro de 2013. 
INSTITUTO DE PESQUISAS ECONÔMICAS APLICADAS; SECRETARIA DE ASSUNTOS ESTRATÉGICOS DA PRESIDÊNCIA DA REPÚBLICA. (2013a). PNAD mostra o aumento da escolaridade média do brasileiro. Brasília: Portal IPEA, 01.10.2013. Disponivel em: http://www. ipea.gov.br/portal/index.php?option=com content\&view $=$ article\&id=20012. Acesso em 11 de outubro de 2013.

\section{CÂMARA DOS DEPUTADOS.}

(s.d.1). Brasília: Câmara dos Deputados, s.d. Disponível em: http://www.camara.gov.br. Acesso em 29 de julho de 2014.

(s.d.2). Resultado da enquete. Brasília, Câmara dos Deputados. Disponível em: http://www2.camara.leg.br/agencia-app/ resultadoEnquete/enquete/CF458143-50F34AD9-9685-61F8B1A5A8C2. Acesso em 19 de novembro de 2014. BRASIL.

\section{MINISTÉRIO DA JUSTIÇA.}

(s.d.3). Infopen. Brasília: Infopen / MJ. Disponivel em: http://portal.mj.gov.br/ main.asp?View=\%7BD574E9CE-3C7D-437AA5B6-22166AD2E896\%7D\&Team=\&params $=$ itemID $=\% 7 \mathrm{BD} 82 \mathrm{~B} 764 \mathrm{~A}-\mathrm{E} 854-4 \mathrm{DC2}-\mathrm{A} 018$ 450D0D1009C7\%7D;\&UIPartUID $=\% 7$ B2868 BA3C-1C72-4347-BE11-A26F70F4CB26\%7D . Acesso em 11 de setembro de 2013.

\section{SENADO FEDERAL.}

(s.d.4). Senado Federal. Disponivel em http://www.senado.gov.br. Acesso em 01 de setembro de 2013.

CALDEIRA, Teresa Pires do Rio.

(1991). Direitos humanos ou 'privilégios de bandidos'? Desventuras da democratização brasileira. CEBRAP. Novos Estudos, N. 30. São Paulo: CEBRAP, Julho de 1991.

CARDIA, Nancy.

(1995). Direitos humanos: ausência de cidadania e exclusão moral. São Paulo: Comissão de Justiça e Paz.

CHIES, Luiz Antonio Bogo; PASSOS, Rodrigo Azevedo.

(2012). Auxílio-reclusão: a bizarra transmutação de um direito social e sua colonização perversa por um populismo punitivo. Textos e Contextos, vol. 11, n. 02; p. 273-291. Disponivel em: http:// revistaseletronicas.pucrs.br/ojs/index.php/ fass/article/viewFile/12386/8637. Acesso em 29 de julho de 2014.

DANTAS, Emanuel de Araújo; RODRIGUES, Eva Batista de Oliveira.

(2009). Auxílio-reclusão: uma abordagem conceitual. Informe da Previdência Social, vol. 21, n. 06. Brasília, junho de 2009. Disponivel em: http://www.previdencia.gov. br/arquivos/office/3_091124-161649-231. pdf . Acesso em 29 de julho de 2014.

\section{DIEESE.}

(2012). A situação do trabalho no Brasil na primeira década dos anos 2000. São Paulo: DIEESE. Disponível em: http://www.dieese.org.br/livro/2012/ livroSituacaoTrabalhoBrasil.pdf. Acesso em 14 de outubro de 2013.

EM RESPOSTA às manifestações, legislativo acelera aprovação de projetos.

(2013). El Economista América, 26 de junho de 2013 [Online]. Disponível em: http://www. eleconomistaamerica.com.br/sociedadeAm-brasil/noticias/4948310/06/13/Emresposta-s-manifestaes-legislativo-aceleraaprovao-de-projetos.html. Acesso em 09 de outubro de 2013.

FERREIRA, Otávio Dias de Souza.

(2014). Agências da Administração Penitenciária de São Paulo com potencial de accountability em direitos humanos no pós-redemocratização. Tese de Mestrado apresentada à Escola de Filosofia, Letras e Ciências Humanas da Universidade Federal de São Paulo. Guarulhos.

FIGUEIRED0, Argelina Cheibub; LIMONGI, Fernando.

(2000). Executivo e Legislativo na nova ordem constitucional. São Paulo: FGV; FAPESP.

FOUCAULT, Michel.

(2003) Vigiar e punir. 27. ed. Petrópolis: Vozes.

(1979) Microfísica do poder. 8. ed. Trad. Roberto Machado. Rio de Janeiro: Edições Graal (Biblioteca de Filosofia e História das Ciências, n. 7). 
GARLAND, David.

(2006). A cultura do controle: crime e ordem social na sociedade contemporânea. Rio de Janeiro: Revan (Pensamento Criminológico, $\left.n^{\circ} 16\right)$.

GODOY, Rafael.

(2014). Uma fila de centenas e centenas de quilômetros: o processo de visitação em penitenciárias do oeste paulista. $38^{\circ}$ Encontro AnualdaANPOCS. Caxambu:ANPOCS. Disponivel em: $\quad$ http://portal.anpocs.org/portal/ index.php?option $=$ com_docman\&task $=$ doc view\&gid=9245\&Itemid=456. Acesso em 11 de novembro de 2014.

HOLSTON, James.

(2008). Dangerous spaces of citizenship: gang talk, rights talk and rule of law in Brazill. In: Insurgent Citizenship: disjunctions of democracy and modernity in Brazil. Princeton: University Press.

LIMONGI, Fernando.

(2013). "Regeneração" da vida pública. 0 Estado de São Paulo, caderno Aliás. São Paulo, 07 de julho de 2013. Disponível em: $\quad$ http://www.estadao.com.br/ noticias/impresso, regeneracao-da-vidapublica-,1051033,0.htm. Acesso em 01 de setembro de 2013.

(2006). Presidencialismo, coalizão partidária e processo decisório. Novos Estudos, 76. São Paulo: CEBRAP, novembro de 2006. Disponivel em: http://www.scielo. br/scielo.php?script=sci_arttext\&pid $=$ S0101-33002006000300002. Acesso em 21 de novembro de 2014.

\section{ORGANIZAÇÃO DAS NAÇÕES UNIDAS.}

(2014). Conselho de Direitos Humanos. Report of the Working Group on Arbitrary Detention. Nova Iorque: 30 de junho de 2014.

PALERMO, Vicente.

(2000). Como se Governa o Brasil? O Debatesobre institucionções Políticas e Gestão de Governo. Dados - Revista de Ciências Sociais, Vol. 43, n. 3. Rio de Janeiro: IUPERJ. Disponível em: http://www.scielo.br/scielo.php?pid=S001152582000000300004\&script=sci_arttext. Acesso em 22 de novembro de 2014.
RAUPP, Daniel.

(2009). Auxílio-reclusão: inconstitucionalidade do requisito baixa renda. Revista CEJ, ano 13, n. 46. Brasília: jul./set. 2009, p. 62-70. Disponivel em: http://www2.cjf. jus.br/ojs2/index.php/revcej/article/ viewFile/1090/1278. Acesso em 29 de julho de 2014.

REPROVAÇÃO ao Congresso sobe nove pontos depois de protesto.

(2013). Folha de São Paulo. São Paulo: 11 de agosto de 2013. Disponivel em: http://www1. folha.uol.com.br/poder/2013/08/1324809reprovacao-ao-congresso-sobe-9-pontosapos-protestos.shtml. Acesso em 11 de setembro de 2013.

RUSCHE, Georg. KIRCHHEIMER, 0 tto.

(2004). Punição e estrutura social. 2. ed. Rio de Janeiro: Revan.

SANTOS, Fabiano. CANELLO, Júlio; CUNHA, Brenda.

(2014a). 0 Congresso e as eleições legislativas de 2014: bancadas partidárias. Boletim do Núcleo de Estudos sobre o Congresso. Rio de Janeiro: IESP/UERJ. Disponivel em: http:// necon.iesp.uerj.br/images/pdf/boletim.pdf. Acesso em 14 de novembro de 2014.

(2014b) 0 Congresso e as eleições legislativas de 2014: perfil ideológico. Boletim do Núcleo de Estudos sobre o Congresso. Rio de Janeiro: IESP/UERJ, 2014b. Disponivel em: http:// necon.iesp.uerj.br/images/pdf/boletim_ ideol.pdf. Acesso em 14 de novembro de 2014.

WACQUANT, LoÏc.

(2011) As prisões da miséria. 2. ed. Rio de Janeiro: Zahar.

\section{Recebido em}

dezembro de 2014

\section{Aprovado em}

maio de 2016 